\title{
Disability rates of bus drivers
}

\author{
P. A. B. RAFFLE 1 \\ London Transport, Griffith House, London NW1
}

\begin{abstract}
Raffle, P. A. B. (1974). British Journal of Industrial Medicine, 31, 152-158. Disability rates of bus drivers. The proposal that ordinary driving licences should be valid up to the age of 70 has stimulated much discussion on the place of medical surveillance in the prevention of road crashes.

London Transport bus drivers are medically examined on entry to the service, after absence from work attributed to sickness or accident for more than 21 days (and in certain other circumstances), and at age 50 and routinely thereafter. Average annual rates of deaths in the service and recommendations for retiral on medical grounds and for transfers to alternative work for these drivers are presented. These disability rates are low even at the older ages. Most of those drivers who were recommended for work other than bus driving were considered to be fit to drive a car. Between ages 50 and $64,85 \%$ of the recommendations for discontinuance of bus driving resulted from post-sickness medical examinations and only $15 \%$ from routine age examinations.

It is concluded that the available evidence supports the legislative proposals for ordinary driving licensing. However, licence holders will need considerable help from their doctors in discharging their legal obligation to notify their licensing authority of medical conditions likely to affect their ability to drive safely.
\end{abstract}

The Secretary of State for the Environment has introduced legislation (Road Traffic Bill 1974) for private car driving licences to be valid from the date of issue to the age of 70 . The present declaration of health at initial issue of a licence would continue but that made at each triennial renewal of the licence would be replaced by a general obligation on the licence holders to notify the Licensing Authority at any time if they became aware of any physical or mental condition which would impair more than temporarily their ability to drive safely. The proposal has been welcomed in some quarters (BMA, 1972) and criticized in others (RoSPA, 1972). It has stimulated enquiry into the value of medical screening of vehicle drivers and the yield of medical conditions

${ }^{1}$ Chief Medical Officer, London Transport Executive Chairman, BMA Joint Panel on Driver Licensing Chairman, Transport Committee, Medical Commission on Accident Prevention important to road safety, which might arise from routine medical examinations of car drivers. Rees (1967) showed that $9 \cdot 2 \%$ of patients in a general practice who drove cars had mental or physical illness which would, in his opinion, render the motorist unsuitable to drive a public service vehicle. On the other hand, Grattan and Jeffcoate (1968) in the United Kingdom, and Herner, Smedby, and Ysander (1970), in Sweden, have suggested that illness in vehicle drivers was responsible for only 1 to 2 per thousand road crashes. They did not include under the heading of illness the effects of drugs and medication on the capacity to drive, nor is it known to what precise extent personality or behavioural abnormalities not amounting to illness contribute to road crashes. Some light can be thrown on the incidence of significant illness from the experience of the medical surveillance of London Transport bus drivers.

It is clear that there cannot be one standard of 
fitness for all types of driver. The risk to other road users from a driver who is unfit can be expressed in the 'equation'

$$
\text { Risk }=\underset{\text { Experience }+ \text { 'Unfitness'. }}{\text { Hours }+ \text { Route }+ \text { Weight }}(+ \text { Load })-
$$

Examining each of these factors in turn, the more hours a driver is at the wheel, the longer he is at risk in meeting a pre-crash situation, in which, of course, bad road behaviour in another driver or in a pedestrian may be a factor. The professional bus (PSV) and lorry (HGV) drivers on schedules find it difficult to stop driving when they feel unwell. Where a driver is confined to mainly urban routes he is surrounded by more people and vehicles to collide with if he loses control than on rural routes. A public service vehicle (PSV) driver is at particular risk in this context because he is continually pulling up where passengers are waiting to board his vehicle. However, urban traffic is usually fairly slow so that, though the number of crashes per million vehicle miles is higher on urban roads than on rural, the proportion of fatal and serious injuries resulting from those crashes is lower. The heavier the weight of the vehicle, the more damage it does to other vehicles or people in a crash. The load carried can also be important: a tanker of one hundred octane petrol is potentially more hazardous than a tanker of milk. Driving experience counteracts the factors mentioned so far. The greater the experience, the less risk there is of a crash because the driver anticipates forthcoming trouble on the road. In this context 'unfitness' means the presence of conditions likely to cause loss of control (collapse or loss of consciousness at the wheel) or impairment of judgment or concentration while driving. On the basis of these factors bus drivers are required to maintain a higher standard of fitness than are car drivers.

London Transport Central Bus drivers (the drivers of the red buses in Central London) are medically examined:

(a) on entry to the service as a driver;

(b) on promotion to driver from conductor (in recent years only those conductors who are likely to be fit to become drivers in the future have been accepted into the service);

(c) after 21 days' absence from work attributed to sickness or accident $(86 \%$ of all spells of sickness absence for drivers terminate in under 21 days);

(d) after absence from work of any duration attributed to vertigo, diseases of the heart and blood vessels, epilepsy, eye disease or eye injury and diabetes;

(e) after failure to complete a shift due to illness;

(f) after sickness absence lasting more than 12 months, to determine whether there is reasonable prospect of resumption of work in the near future or whether retirement on medical grounds is indicated;

(g) routine age examinations:

(1) prior to 1 October 1970 , on attaining the ages of 50,56, 62, 64 and annually thereafter, and

(2) (so as to be compatible with the new public service vehicle medical examination requirements issued by the Commissioner of Police for the Metropolis) from 1 October 1970 at ages 50 and at the PSV licence renewal following the 50th, 56th, 59th, 62nd, 64th birthdays and annually thereafter;

(h) at any time at the request of management, of the driver, or of the driver's doctor;

(i) for re-examination (surveillance) at the request of the London Transport medical officer.

The normal retirement age for drivers is 65 . Some volunteer to continue and stay on to the age of 70 , subject to the wish of management and annual medical examinations. Only about $3 \%$ of the drivers are aged 65-69.

The medical standards used for the surveillance of bus drivers are broadly those indicated for PSV drivers in Medical Aspects of Fitness to Drive (Medical Commission on Accident Prevention, 1971). Any driver who at any of the above medical examinations is found not fit, either temporarily or permanently, to continue to drive a bus is recommended for alternative work within the organization. If he is unfit for any kind of work within London Transport he is recommended for retirement on medical grounds.

\section{Method}

Since 1948 the Central Record of Staff Statistics (London Transport Executive, 1956) has maintained three files of punched cards:

(1) a main file in which there is one card for each member of the staff, which records inter alia the job undertaken (grade), date of birth, and date of entry into service and which is continually kept up to date;

and for a large proportion of staff, including drivers,

(2) a sickness absence file which contains one card for each spell of absence attributed to sickness with the personal details of the employee from (1), the date of commencement of spell, duration of absence, and diagnosis from medical certificates submitted or the diagnosis recorded by one of the London Transport medical officers. The data from this file are not further used in this paper but they have enabled a running check to be kept that all drivers are medically examined in accordance with categories $(c),(d)$ and $(f)$ above;

(3) a wastage file which contains one card for each movement out of a grade with the personal details of the employee from (1) above and the reason for leaving, e.g., resignation, age retirement, death, voluntary 
transfer, transfer to alternative work, and retirement on medical grounds either because alternative work is not available or because he is unfit for alternative work. For deaths, the death certificate is seen for pension purposes and the cause of death is extracted and entered on the cards. Where there is a recommendation for transfer to alternative work or for retirement on medical grounds, the diagnosis recorded by the London Transport medical officer is entered on the wastage card.

Diagnoses are coded according to the International Statistical Classification of Diseases, Injuries and Causes of Death, using the 6th Revision up to 31 December 1967 and the 8th Revision from 1 January 1968 (WHO, 1967). The diagnoses are then grouped into 20 broad diagnostic groups (BDGs), as detailed in Ager and Raffle (1973).

From the data contained in the main file and the wastage file the average annual disability rates for Central Bus drivers for the years 1967-71 inclusive have been calculated and presented in the form of rates:

(a) of deaths in service;

(b) of recommendations for retirement on medical grounds; and

(c) of recommendations for alternative work, whether or not such work was available.

In addition, certain data and statistics about preemployment and age medical examinations maintained within the Medical Service are also presented.

On 1 January 1967, 13949 drivers were employed and 12891 on 31 December 1971; 13088 new drivers joined the grade during the period, more than $50 \%$ of whom were below the age of 30 .

\section{Results}

\section{Pre-employment medical examinations}

During the five years, 17048 potential direct recruits to the grade of bus driver were medically examined. Of these, $821(4.8 \%)$ were found to be unfit for appointment; $406(49.5 \%$ of those failing or $2.4 \%$ of the total examined) had vision below the entrance standard of $6 / 9,6 / 12$ with glasses, $6 / 60,6 / 60$ without glasses, normal visual fields, and absence of strabismus; 253 (13.8\% of those failing) had disorders of the cardiovascular system, mainly valvular disease or a raised blood pressure for the age of the applicant. There was no other important single cause of rejection. In addition, $443(2.6 \%)$ were temporarily deferred, mainly to obtain suitable glasses, and some for investigation of glycosuria or albuminuria. Many of these subsequently joined the service as drivers and are included in those who passed the preemployment medical examination.

\section{Deaths in the service}

There were 242 deaths in the grade in service during the five years. The age specific death rates are shown in Table 1. It is not surprising that the rates are considerably below those for the male population of England and Wales as a whole. For instance, the Registrar General (1973) records the death rate for males aged 55-64 for the years $1966-70$ as $21 \cdot 1$ per thousand, whereas the drivers' rate (recalculated from the age grouping) was $\mathbf{1 0 . 3}$ per thousand. This is partly due to initial selection procedures, partly to selection out of the driver population of those becoming ill, and partly to deaths after leaving the service on retirement on medical grounds or after transfer to alternative work within the organization being excluded from the drivers' figures.

(For all the tables of rates, figures for the age group 65 and over are in italics to draw attention to the highly selective nature of this group.)

Thirty-two per cent of the deaths were attributed to neoplasm and $37 \%$ to diseases of the cardiovascular system, but in the 60-64 age group $43 \%$ of the deaths were attributed to neoplasm and only $36 \%$ to diseases of the cardiovascular system.

\section{Retirement on medical grounds}

During the period 961 men were considered not to be fit to continue as drivers, 862 of whom were known to have been recommended for alternative work. In 16 instances there is no record whether alternative work or retirement on medical grounds was initially recommended. These 16 cases have been added to the 83 known to have been recom-

TABLE 1

Death Rates of Bus Drivers 1967-71

Rates Per 1000 MaN Years EXPOSED to RisK-All Diagnoses

\begin{tabular}{c|c|c|c}
\hline $\begin{array}{c}\text { Age attained } \\
\text { in year of death }\end{array}$ & $\begin{array}{c}\text { Number exposed } \\
\text { to risk }\end{array}$ & $\begin{array}{c}\text { Number of } \\
\text { deaths }\end{array}$ & $\begin{array}{c}\text { Rate } \\
\text { per 1 000 }\end{array}$ \\
\hline Up to 29 & 14893 & 6 & 0.40 \\
$30-39$ & 16372 & 15 & 0.92 \\
$40-49$ & 12666 & 24 & $1 \cdot 89$ \\
$50-54$ & 5964 & 27 & 4.53 \\
$55-59$ & 7286 & 66 & $9 \cdot 06$ \\
$60-64$ & 6229 & 29 & 14.92 \\
65 and over & 1944 & 29 & \\
All ages & 65354 & 243 & \\
\hline
\end{tabular}


TABLE 2

Disability Rates of Bus Drivers 1967-71

RATES PER 1000 Man Years EXPOSED to RisK-All Diagnoses

\begin{tabular}{|c|c|c|c|c|c|c|c|}
\hline \multirow[t]{2}{*}{$\begin{array}{l}\text { Age attained } \\
\text { in year of transfer }\end{array}$} & \multirow{2}{*}{$\begin{array}{l}\text { Number } \\
\text { exposed } \\
\text { to risk }\end{array}$} & \multicolumn{2}{|c|}{$\begin{array}{c}\text { Recommended } \\
\text { for retiral } \\
\text { on medical grounds }\end{array}$} & \multicolumn{2}{|c|}{$\begin{array}{c}\text { Recommended } \\
\quad \text { for } \\
\text { alternative work }\end{array}$} & \multicolumn{2}{|c|}{ Total $^{2}$} \\
\hline & & No. & Rate & No. & Rate & No. & Rate \\
\hline $\begin{array}{c}\text { Up to } 29 \\
30-39 \\
40-49 \\
50-54 \\
55-59 \\
60-64 \\
65 \text { and over } \\
\text { All ages }\end{array}$ & $\begin{array}{r}14893 \\
16372 \\
12666 \\
5964 \\
7286 \\
6229 \\
1944 \\
65354\end{array}$ & $\begin{array}{r}6 \\
12 \\
19 \\
10 \\
14 \\
24 \\
14\end{array}$ & $\begin{array}{l}0.40 \\
0.73 \\
1.50 \\
1.68 \\
1.92 \\
3.85 \\
7 \cdot 20\end{array}$ & $\begin{array}{r}41 \\
56 \\
114 \\
122 \\
206 \\
294 \\
29\end{array}$ & $\begin{array}{r}2 \cdot 75 \\
3 \cdot 42 \\
9 \cdot 00 \\
20 \cdot 46 \\
28 \cdot 27 \\
47 \cdot 20 \\
14 \cdot 92\end{array}$ & $\begin{array}{r}47 \\
68 \\
133 \\
132 \\
220 \\
318 \\
43\end{array}$ & $\begin{array}{r}3 \cdot 15 \\
4 \cdot 15 \\
10 \cdot 50 \\
22 \cdot 14 \\
30 \cdot 19 \\
51 \cdot 05 \\
22 \cdot 12\end{array}$ \\
\hline Numbers & & 99 & & 862 & & 961 & \\
\hline
\end{tabular}

mended for retirement on medical grounds because, from experience, it is known that the most likely case of this kind not to be classified is where a driver has been off sick for more than a year and was visited at his home or in hospital. Many of these cases are terminal and therefore are likely to be recommended for retirement on medical grounds. Another reason for adding the unknowns to those recommended for retirement on medical grounds rather than to those recommended for alternative work was that the opposite action could have been claimed artificially to boost the conclusions which eventually emerge from the results. Table 2 shows the age specific rates for recommendations for retirement on medical grounds for the 99 cases.
Transfers to alternative work

Table 2 also shows the age specific rates for those drivers recommended for transfer to alternative work either temporarily or permanently and the total disability rates (except deaths). It will be seen that $90 \%$ of all the disabilities, and of those occurring under the age of 65 , resulted in a recommendation for transfer to alternative work rather than retirement on medical grounds. This is important because nearly all of these men, though no longer fit to drive a bus, would have been fit to drive a private car at least for social purposes. In fact, approximately 70 men who had been transferred to alternative work resumed bus driving with London Transport during the five years. One hundred and fifty-

TABLE 3

Disability Rates of Bus DRIVERS 1967-71' Rates Per 1000 Man Years Experience in Broad Diagnostic Groups

\begin{tabular}{|c|c|c|c|c|c|c|c|c|c|}
\hline \multirow[b]{2}{*}{$\begin{array}{c}\text { Age } \\
\text { attained }\end{array}$} & \multirow[b]{2}{*}{$\begin{array}{c}\text { Average } \\
\text { no. of men }\end{array}$} & \multicolumn{7}{|c|}{ Broad diagnostic group } & \multirow[b]{2}{*}{ Total $^{2}$} \\
\hline & & $\begin{array}{c}\text { Functional } \\
\text { nervous } \\
\text { disorders }\end{array}$ & $\begin{array}{c}\text { Organic } \\
\text { nervous } \\
\text { disorders }\end{array}$ & $\begin{array}{l}\text { Diseases } \\
\text { of the eye }\end{array}$ & $\begin{array}{c}\text { Diseases } \\
\text { of the. } \\
\text { circulatory } \\
\text { system }\end{array}$ & Bronchitis & $\begin{array}{c}\text { Diseases } \\
\text { of bones } \\
\text { and organs } \\
\text { of } \\
\text { movement }\end{array}$ & $\begin{array}{l}\text { Miscel- } \\
\text { laneous }\end{array}$ & \\
\hline $\begin{array}{c}\text { Up to } 29 \\
30-39 \\
40-49 \\
50-54 \\
55-59 \\
60-64 \\
65 \text { and over }\end{array}$ & $\begin{array}{r}14893 \\
16372 \\
12666 \\
5964 \\
7286 \\
6229 \\
1944\end{array}$ & $\begin{array}{l}0.672 \\
0.549 \\
0.869 \\
0.503 \\
1.097 \\
2.890 \\
1.543\end{array}$ & $\begin{array}{l}0.470 \\
0.366 \\
0.395 \\
1.509 \\
1.235 \\
1.927 \\
1.029\end{array}$ & $\begin{array}{l}0.403 \\
0.061 \\
0.316 \\
0.839 \\
1.646 \\
2.248 \\
0.514\end{array}$ & $\begin{array}{r}0 \cdot 336 \\
0 \cdot 733 \\
4 \cdot 264 \\
12 \cdot 743 \\
15 \cdot 783 \\
20 \cdot 388 \\
7 \cdot 202\end{array}$ & $\begin{array}{l}-\overline{1} \\
0 \cdot 122 \\
0 \cdot 158 \\
0.670 \\
1 \cdot 647 \\
4.977 \\
1 \cdot 543\end{array}$ & $\begin{array}{l}0 \cdot 134 \\
0 \cdot 427 \\
1 \cdot 185 \\
2 \cdot 347 \\
1 \cdot 509 \\
5.940 \\
1.029\end{array}$ & $\begin{array}{l}0.403 \\
1 \cdot 039 \\
1 \cdot 343 \\
1 \cdot 844 \\
3 \cdot 706 \\
5 \cdot 458 \\
5 \cdot 144\end{array}$ & $\begin{array}{r}3 \cdot 156 \\
4 \cdot 212 \\
10 \cdot 505 \\
22 \cdot 133 \\
30 \cdot 189 \\
51.056 \\
22 \cdot 118\end{array}$ \\
\hline $\begin{array}{l}\text { All ages } \\
\text { No. of di } \\
\text { Perce }\end{array}$ & $\begin{array}{l}65354 \\
\text { bilities } \\
\text { age }\end{array}$ & $\begin{array}{l}0.949 \\
62 \\
6.5\end{array}$ & $\begin{array}{l}0 \cdot 765 \\
50 \\
5 \cdot 2\end{array}$ & $\begin{array}{l}0.658 \\
43 \\
4 \cdot 5\end{array}$ & $\begin{array}{l}6 \cdot 152 \\
402 \\
41 \cdot 8\end{array}$ & $\begin{array}{c}0.827 \\
54 \\
5.6\end{array}$ & $\begin{array}{l}1 \cdot 346 \\
88 \\
9 \cdot 2\end{array}$ & $\begin{array}{c}1.867 \\
122 \\
12.7\end{array}$ & $\begin{array}{c}14 \cdot 706 \\
961 \\
100\end{array}$ \\
\hline
\end{tabular}

${ }^{1}$ Excluding deaths

'The rates in this column do not necessarily correspond with the totals in other Tables because of 'rounding up'. 
TABLE 4

Disability RATES OF Bus DRIVERS 1967-71 1

from All Medical Examinations and from Routine Age Examinations

RATES PER 1000 MAN YeARS EXPOSED TO RISK

\begin{tabular}{|c|c|c|c|c|c|}
\hline \multirow{3}{*}{$\begin{array}{c}\text { Age attained } \\
\text { in year of } \\
\text { transfer }\end{array}$} & \multirow{3}{*}{$\begin{array}{l}\text { Number } \\
\text { exposed } \\
\text { to risk }\end{array}$} & \multicolumn{4}{|c|}{ Recommended as unfit } \\
\hline & & \multicolumn{2}{|c|}{ At all medical examinations } & \multicolumn{2}{|c|}{ At age medical examinations } \\
\hline & & No. & Rate & No. & Rate \\
\hline $\begin{array}{l}50-54 \\
55-59 \\
60-64\end{array}$ & $\begin{array}{l}5964 \\
7286 \\
6229\end{array}$ & $\begin{array}{l}132 \\
220 \\
318\end{array}$ & $\begin{array}{l}22 \cdot 13 \\
30: 19 \\
51 \cdot 05\end{array}$ & $\begin{array}{l}21 \\
27 \\
55\end{array}$ & $\begin{array}{l}3 \cdot 52 \\
3 \cdot 71 \\
8 \cdot 83\end{array}$ \\
\hline Total & & 670 & $34 \cdot 39$ & 103 & 5.29 \\
\hline
\end{tabular}

${ }^{1}$ Excluding deaths in service

three drivers could not be found alternative work and left the service. These were mainly younger men with short durations of service. Some of these men could also have been fit to resume driving subsequently.

\section{Broad diagnostic groups}

Table 3 shows the distribution of the total disability rates (except deaths) in the seven broad diagnostic groups containing more than 40 disabilities. The importance of diseases of the cardiovascular system is again apparent, accounting for $42 \%$ of the cases. Bronchitis and diseases of bones and organs of movement become important in the older age groups.

\section{Age medical examinations}

The disability rates so far presented have included the outcome of routine age medical examinations of drivers as well as post-sickness and post-accident medical examinations. Because age medical examinations only start at age 50 and because of the selected nature of the population over 65, comparison between the two groups of medical examinations is possible only between the ages of 50 and $64(64.4 \%$ of the drivers in these age groups had completed more than 20 consecutive years in the grade).

Between the ages of 50 and 64, 670 drivers were recommended for retirement on medical grounds or for transfer to alternative work. Of these, only 103 $(15 \%)$ were as the result of an age medical examination. Table 4 shows the total disability rates (except deaths) for three age groups and those which were picked up at age medical examinations. The rate of disabilities leading to transfer from driving found at age medical examinations was only $5 \cdot 3$ per thousand. Table 5 shows that $78 \%$ of the disabilities found at age examinations were due to cardiovascular abnormalities, in particular hypertension. Morris et al. (1966) and Morris (1973) have demonstrated the importance of hypertension as a risk factor in middle-aged London busmen in the subsequent development during the next 5 and 10 years of ischaemic heart and cerebrovascular disease. Among the 'other CVS' were six previously unsuspected cases of ischaemic heart disease and seven of auricular fibrillation or heart block. Less than $5 \%$ of the disabilities were due to visual defects. Tables 3 and 5 together show that 80 out of $402(20 \%)$ of the cases of cardiovascular disability were found at age medical examinations. Only 5 out of 43 $(11.6 \%)$ of the cases of visual disability were so

TABLE 5

Disabilities Discovered at Routine Age Examinations of Bus Drivers 1967-71

\begin{tabular}{c|c|c|c|c|c}
\hline $\begin{array}{c}\text { Age attained } \\
\text { in year of } \\
\text { examination }\end{array}$ & Hypertension & $\begin{array}{c}\text { Other } \\
\text { cardiovascular }\end{array}$ & Vision & Miscellaneous & Total \\
\hline $50-54$ & 13 & 7 & 1 & -1 & 21 \\
$55-59$ & 21 & 3 & 2 & 17 & 55 \\
$60-64$ & 30 & 6 & 5 & 18 & 103 \\
\hline Total & 64 & 16 & 2 & & 17 \\
\hline
\end{tabular}


found. The 43 cases of visual defect were of pathological conditions of the eye, not correctable by glasses. These conditions appear therefore to cause illness leading to post-sickness medical examinations rather than silent conditions recognized at routine medical examinations.

\section{Discussion}

The number of road crashes and casualties in Great Britain fell in 1967 and subsequently started to rise slowly again (Department of the Environment, 1972a). There are a number of factors producing these changes, but mainly the alcohol provisions in the Road Safety Act 1967 (incorporated in the Road Traffic Act 1972) on drinking and driving, and the steady transference of young people from twowheeled vehicles to motor cars with their far lower casualty rate per hundred million miles driven. Unfortunately, the casualties for car drivers and passengers are increasing and are rising faster in the 20-29 age group than in the older age groups. The casualty rate per thousand persons for car drivers is more than two and a half times greater in the 20-29 age group than in the 50-59 age group, yet it is in the younger group (Havard, 1973) that medical conditions are least likely to be present and that the various bodily functions thought to be important in driving, such as eyesight and reaction time, are at their best. The age groups which incur the least risk of accident are those in which medical conditions are most likely to occur and in which the various faculties are already subject to the degenerative process of advancing age.

Cornwall (1962) showed that the average annual rate of reported bus accidents among London Transport bus drivers fell with increasing age and length of service in the grade to such an extent that the rate for drivers aged 60-64 with more than 14 years' service was a quarter of that of drivers under 30 with less than four years' service.

The author (Raffle, 1974) reported that during the years 1953-72 there were 108 incidents of London Transport bus drivers becoming sufficiently ill in the cab that they either had to discontinue driving or actually collapsed at the wheel. These incidents caused 54 accidents varying in severity from a scrape of paint off a vehicle to another road user being killed. Putting the figures into perspective, during the 20 years there were 343600 driver years of experience, during which they drove $6.3000 \mathrm{~m}$. miles or one accident for every $115 \mathrm{~m}$. miles driven. ing.

The following general picture is therefore emerg-

Road crashes and casualties among car drivers are increasing, especially in the younger age groups.
Disabilities likely to impair the ability to drive safely increase with age, whereas the driver's risk of being killed or injured in a road accident decreases at least to the age of 65 .

The proportion of road crashes which can be attributed to previously ascertainable illness is very small.

Under the present law, a driver can drive legally until the next licence renewal (up to three years), even though he is aware that he is suffering from a condition likely to make him a danger to other road users.

Rates of disability rendering a bus driver unfit to drive a bus are small, even in the 60-64 age group, and nearly all are still fit to drive a car socially (i.e., non-professionally).

Eighty-five per cent. of the disabilities rendering a bus driver unfit to drive a bus were picked up at post-sickness and post-accident examinations on the occasions described in the introduction and only $15 \%$ at routine age examinations.

Evidence from this and other studies therefore suggests that routine medical screening of private car licence holders (i.e., excluding the first application and after the age of 70 on which there is little evidence) by health declaration, by questionnaire or by medical examination would not contribute significantly to road safety. Medical surveillance at the time of or after sickness would yield greater though small dividends. Because of the small contribution which illness in drivers makes to the causation of road crashes, the flexible arrangements proposed by the Secretary of State seem reasonable. The legal obligation on licence holders to notify the licensing authorities of relevant disabilities when they become aware of them would enable selective screening, appropriate to the disability revealed, to be carried out. This screening could be by a further declaration of health or by a medical questionnaire or by enquiry of the licence holder's own medical adviser or by medical examination.

The vast majority of road accidents in which the driver is at fault are the result of irresponsible behaviour (Raffle, 1973), including driving while temporarily unwell or under the influence of medication for an illness. It will remain the responsibility of the driver not to drive while the ability to drive properly is impaired by illness but this responsibility cannot be exercised effectively unless he is given the necessary advice and guidance. In the words of the Minister for Transport Industries (Department of the Environment, 1972b) 'The Minister looks to doctors to advise their patients not to drive if they consider them unfit to do so. He would also expect doctors to remind patients whose driving ability is affected more than temporarily by illness or disability to notify the licensing authority in accordance with the proposed new statutory obligation.' 
The statistical data in this paper were provided by $\mathrm{Mr}$. R. W. Willsmore, FIA, Staff Administration Officer, and his staff in the Central Record of Staff Statistics and the Actuarial Sections of London Transport. These data were in turn based on the clinical work of my colleagues in the Medical Service of London Transport.

I am greatly indebted to them all and to other friends who have commented on the drafts, including Dr. J. L. Fyfe, Dr. J. D. J. Havard, and Mr. J. E. Ager, BSc, FIA. However, the opinions expressed are my own.

\section{References}

Ager, J. E. and Raffle, P. A. B. (1973). Patterns in Sickness Absence. London Transport Executive, London.

British Medical Association (1972). Proceedings of Council. British Medical Journal, 1, Supplement, 30.

Cornwall, C. J. (1962). The accident experience of London bus drivers. Annals of Occupational Hygiene, 5, 69-82.

Department of the Environment (1972a). Road Accidents 1970. HMSO, London.

- (1972b). Press Notice, 26 September 1972.

Grattan, E. and Jeffcoate, G. O. (1968). Medical factors and road accidents. British Medical Journal, 1, 75-79.

Havard, J. D. J. (1973). Proceedings of Public Works Congress 1972, pp. 482-506.

Herner, B., Smedby, B., and Ysander, L. (1970). Sudden illness as a cause of motor-vehicle accidents. Acta Chirurgica Scandinavica, Supplement 409, 30-32.
London Transport Executive (1956). Health in Industry. Butterworth, London.

Medical Commission on Accident Prevention (1971). Medical Aspects of Fitness to Drive, 2nd edition, edited by Andrew Raffle. Medical Commission on Accident Prevention, London.

Morris, J. N. (1973). Four cheers for prevention. Proceedings of the Royal Society of Medicine, 66, 225-232.

, Kagan, A., Pattison, D. C., Gardner, M. J., and Raffle, P. A. B. (1966). Incidence and prediction of ischaemic heart-disease in London busmen. Lancet, 2, 553-559.

Raffle, P. A. B. (1973). Medical Commission on Accident Prevention Annual Report 1972-73 (In press). (1974). Transactions of the Medical Society of London (In press).

Rees, W. D. (1967). Physical and mental disabilities of 1,190 ordinary motorists. British Medical Journal, 1, 593-597.

Registrar General (1973). Statistical Review of England and Wales for the year 1971, Part I. HMSO, London.

Royal Society for the Prevention of Accidents (1972). CARE on the Road, October issue, p. 1.

World Health Organization (1967). Manual of the International Statistical Classification of Diseases, Injuries and Causes of Death, 8th revision. WHO, Geneva.

Received for publication July 26, 1973.

Accepted for publication October 18, 1973. 